\title{
External Iliac Vein Injury During the Bipolar Transurethral Resection of Bladder Tumor: A Case Report
}

\author{
Sacit Nuri Gorgel ${ }^{\mathrm{a}, \mathrm{b}}$, Osman Kose ${ }^{\mathrm{a}}$, Ozan Horsanali ${ }^{\mathrm{a}}$, Ersoy Uysal ${ }^{\mathrm{a}}$, Kutan Ozer ${ }^{\mathrm{a}}$, \\ Emin Ozbek $^{\mathrm{a}}$
}

\begin{abstract}
Incidence of carcinoma bladder is increasing in industrialized and developed countries. Most of tumors are superficial and well differentiated transitional cell carcinomas. Transurethral resection of bladder tumor is a routinely performed procedure for bladder tumors. This procedure is more likely to stimulate the adjacent obturator nerve, which is in close proximity to the lateral bladder wall. This stimulation causes obturator nerve reflex, leading to inadvertent bleeding and bladder perforation.
\end{abstract}

Keywords: Bipolar transurethral resection; Bladder tumor; Vein injury

\section{Introduction}

Bladder cancer is one of the most common malignant diseases of the urinary tract system. According to the American Cancer Society, approximately 74,690 new cases of bladder cancer and 15,580 bladder cancer-related deaths occurred in 2014 [1]. Approximately $75 \%$ of patients with bladder cancer present with non-muscle-invasive bladder cancer (NMIBC, formerly known as superficial bladder cancer) that is confined to either the mucosa (stage Ta, carcinoma in situ) or submucosa (stage T1). The current standard treatment for NMIBC is transurethral resection of bladder tumor (TURBT), followed by adjuvant intravesical chemotherapy or immunotherapy [2].

The goals of TURBT are to eradicate all visible tumors, prevent tumor recurrence and prevent progression to invasive or metastatic disease. However, when the lesions are located in the lateral bladder wall or around the ureteral orifice, optimal penetration is difficult to control during TURBT, and

Manuscript accepted for publication November 04, 2015

azmir Katip Celebi University, Ataturk Training and Reseacrh Hospital, Department of Urology, Izmir, Turkey

${ }^{b}$ Corresponding Author: Sacit Nuri Gorgel, Izmir Katip Celebi University, Ataturk Training and Reseacrh Hospital, Department of Urology, Izmir, Turkey.Email: sngorgel@hotmail.com

doi: http://dx.doi.org/10.14740/jmc2359w complications such as bleeding, bladder perforation and hydronephrosis can occur. In addition, these procedures are more likely to stimulate the adjacent obturator nerve $(\mathrm{ON})$, which is in close proximity to the lateral bladder wall. This stimulation causes obturator nerve reflex (ONR), leading to inadvertent bleeding and bladder perforation [3].

\section{Case Report}

A 52-year-old male patient was admitted to our clinic because of macroscopic hematuria. Physical examination, urine analysis, complete blood count and blood biochemistry were normal. A mass, $2 \mathrm{~cm}$ diameter, was detected on urinary system ultrasonography. Papillary tumoral mass was shown in left side wall of the bladder on cystoscopy. Then bipolar transurethral resection of tumor was planned under spinal anesthesia. Bladder perforation and gross hematuria occurred during transurethral resection of tumor due to severe ONR. We decided to perform open surgery due to persistence of hematuria, the occurrence of hypotension and tachycardia. Bladder perforation about $1 \mathrm{~cm}$ at left side wall and left external iliac vein injury were seen in open surgery. The left external iliac vein injury was repaired with 5-0 prolene suture and bladder perforation was repaired with 3-0 vicryl suture. Pathologic evaluation of transurethral resection was reported as low grade urothelial carcinoma. Cystoscopy was normal after 3 months from open surgery.

\section{Discussion}

ON originates from L2-L4 lumber plexus and passes through obturator foramen to supply adductor muscles of thigh. It passes close to infero-lateral bladder wall, bladder neck and prostatic urethra [4].

In transurethral urological surgeries, bladder is distended with irrigation fluid. ON path comes very close to the lateral bladder wall. Electric current can easily stimulate the $\mathrm{ON}$ while doing TURBT. Stimulation of ON causes sudden jerk (adductor reflex) due to contraction of adductor muscles. This all happens in fraction of a second and may lead to bladder perforation or deep cut which may cause profuse bleeding. This may also result in incomplete resection of the bladder tumor 
$[5,6]$.

Motor part of the $\mathrm{ON}$ is blocked under spinal anesthesia; however, jerk does occur due to non-blockage of sensory part. D-tubocurarine and succinylcholine have been used to block neuromuscular junction but this requires a general anesthesia with endotracheal intubation. However, morbidity is relatively high in old age patients requiring tumor surgery under general anesthesia $[7,8]$.

Prentiss was the first person who used regional block of ON in 1965 [9]. Various techniques of obturator nerve block (ONB) were described in literature [10-12].

\section{Conclusion}

ONB along with spinal anesthesia can be safely employed to prevent the obturator jerk, which commonly occurs in tumors of posterolateral areas of bladder. We recommend ONB in patient of lateral bladder tumor undergoing TURBT. Vascular injury should be considered in the presence of persistence of hematuria, hypotension and tachycardia due to ONR and open surgery should be performed.

\section{Conflict of Interest}

The authors declare that they have no conflict of interest.

\section{References}

1. Siegel R, Ma J, Zou Z, Jemal A. Cancer statistics, 2014. CA Cancer J Clin. 2014;64(1):9-29.

2. Babjuk M, Burger M, Zigeuner R, Shariat SF, van Rhijn BW, Comperat E, Sylvester RJ, et al. EAU guidelines on non-muscle-invasive urothelial carcinoma of the bladder: update 2013. Eur Urol. 2013;64(4):639-653.

3. Golan S, Baniel J, Lask D, Livne PM, Yossepowitch O. Transurethral resection of bladder tumour complicated by perforation requiring open surgical repair - clinical characteristics and oncological outcomes. BJU Int. 2011;107(7):1065-1068.

4. Berberoglu M, Uz A, Ozmen MM, Bozkurt MC, Erkuran C, Taner S, Tekin A, et al. Corona mortis: an anatomic study in seven cadavers and an endoscopic study in 28 patients. Surg Endosc. 2001;15(1):72-75.

5. Mydlo JH, Weinstein R, Shah S, Solliday M, Macchia RJ. Long-term consequences from bladder perforation and/or violation in the presence of transitional cell carcinoma: results of a small series and a review of the literature. $\mathbf{J}$ Urol. 1999;161(4):1128-1132.

6. Junne-Yin Kuo. Prevention of Obturator Jerk during Transurethral Resection of Bladder Tumor. JTUA. 2008;19:27-31,

7. Hobika JH, Clarke BG. Use of neuromuscular blocking drugs to counteract thigh-adductor spasm induced by electrical shocks of obturator nerve during transurethral resection of bladder tumors. J Urol. 1961;85:295-296.

8. Cesur M, Erdem AF, Alici HA, Yapanoglu T, Yuksek MS, Aksoy Y. The role of succinylcholine in the prevention of the obturator nerve reflex during transurethral resection of bladder tumors. Saudi Med J. 2008;29(5):668-671.

9. Prentiss RJ, Harvey GW, Bethard WF, Boatwright DE, Pennington RD. Massive Adductor Muscle Contraction in Transurethral Surgery: Cause and Prevention; Development of Electrical Circuitry. J Urol. 1965;93:263-271.

10. Choquet O, Capdevila X, Bennourine K, Feugeas JL, Bringuier-Branchereau S, Manelli JC. A new inguinal approach for the obturator nerve block: anatomical and randomized clinical studies. Anesthesiology. 2005;103(6):1238-1245.

11. Baba M, Nishihara L, Tomi K. [Pubic tubercle side approach to the obturator nerve block]. Masui. 2007;56(10):1174-1178.

12. Khorrami MH, Javid A, Saryazdi H, Javid M. Transvesical blockade of the obturator nerve to prevent adductor contraction in transurethral bladder surgery. J Endourol. 2010;24(10):1651-1654. 